that the pulse rate had dropped to 86 , but within eight hours it had risen again and death occurred on the same day. Although no records were made with the polygraph, there is little doubt that most of the apparent slowing in this instance was due to the production of extrasystoles.

CASE X.-C. W., colored, aged fourteen years. Endocarditis; pericarditis; acute articular rheumatism. Patient when seen was sitting up in bed, gasping and very weak: pulse rate was regular, and 124 to the minute. It was decided to give her an injection of. $\frac{1}{60}$ gr. strophanthin, with the fatal effect observed in the previous discussion.

\title{
THE VALUE OF COLONIC INFLATION IN THE DIAGNOSIS OF CHRONIC APPENDICITIS. ${ }^{1}$
}

\author{
By Edward H. Goodman, M.D., \\ ASGOCIATE IN MEDICINE, UNIVERSITY OF PENNSYLVANIA, PHILADELPHIA, \\ AND \\ Charles W. Lüders, M.D., \\ CYNWYD, PENNSYLVANIA.
}

THe frequent association of chronic inflammation of the appendix with persistent gastro-intestinal disturbances is being more and more recognized, but the diagnosis of chronic or subacute appendicitis is, nevertheless, a matter of no little difficulty, particularly in those cases which have had no history of a previous acute attack. In many instances, pain in the right iliac fossa, either spontaneous or induced by pressure, furnishes the clue to the diagnosis, but in many other instances there is an absence of this feature, the chief symptom being abdominal pain of more or less definiteness. Granting that there is well-marked pain in the right iliac fossa, one is still not justified in concluding that the cause of the pain is appendicular in origin, without excluding disease of organs situated in the right upper and lower quadrant of the abdomen, notably the Fallopian tube, ovary, kidney, and gall-bladder, a matter at times beset with difficulty.

The frequent occurrence of latent appendicitis and the difficulty attending its diagnosis has led Bastedo to advance a new test, the dilatation test, in order to determine the presence of chronic appendicitis. He passes a colon tube, eleven or twelve inches, into the rectum and injects air by means of an atomizer bulb. "If, as the colon distends, pain and tenderness to finger-point

1 Read at a meeting of the American Gastro-enterological Society, Atlantic City, June 22 and $23,1914$. 
pressure become apparent at McBurney's point there is appendicitis," to use Bastedo's own words."

The test is not needed in an acute appendicitis and is not required in an undoubted chronic case, but the indication for the method lies in individuals with persistent digestive and abdominal disturbance for which no cause can be found. Also in distinguishing between right-sided pelvic inflammation and an inflamed appendix the test is said to be of assistance. Bastedo concludes his article with the statement: "In the use of the test during the last four years we have had no case in which the test was positive and the operation findings negative. But in two out of all our cases the negative finding of the test was followed within six months by a typical attack of appendicitis, and the test was, therefore, presumably at fault. Several times in the early days of the test surgeons operated for a suspected appendicitis, though the test was negative, and in every such case the appendix was found normal."

Such promise of an easy method of diagnosis has led subsequent observers to study the test, among them being Dreyer, ${ }^{3}$ Rost, ${ }^{4}$ Slawinski, ${ }^{5}$ and most recently Hertz. ${ }^{6}$ The last-named is particularly enthusiastic and agrees with Bastedo, to wit, that the test is an almost infallible means of diagnosing chronic appendicitis. $\mathrm{He}$ warns against its use in cases of acute inflammatory disease of the appendix unless the surgeon is prepared to operate at once, as there is imminent danger of tearing adhesions or causing a diseased appendix to perforate.

Hertz has shown that the only stimulus to visceral pain is distention, but so long as the colon is healthy the pain appears no sooner in the appendix than in the rest of the colon. If there is inflammation of the appendix there is an increased response to the pain stimulus of visceral distention, pain is much more rapidly produced, and as a result, local pain and tenderness are observed in the right iliac fossa. Adhesions do not seem to be the main factor in the production of the pain, as some cases exhibited typical pain without these being present.

Rost $^{7}$ claims that the test is not a specific one for appendicitis, but that the condition of the lower bowel may be similarly recognized by the pain which follows colonic inflation. He quotes, as exemplifying this contention, a case of cecum mobile, which after a fixation of the cecum experienced no pain on inflation, and a case of pain in the left iliac fossa which was shown at operation to be due to chronic adhesions.

Slawinski $i^{8}$ has made use of the method for some time and suggests that it be called Bastedo's test.

2 Amer. Jour. Med. ScI., 1911, exlii, 11.

3 Münch. med. Woch., 1912, p. 1845.

Ibid., 1912, p. 2055.

' Loc. cit.

${ }^{4}$ Ibid., 1912, p. 2055.

${ }^{6}$ Lancet, 1913, i, 816.

${ }^{8}$ Loc. cit. 
The preciseness of the results claimed for colonic inflation has induced us to study the patients admitted to the Presbyterian Hospital during the past year.

The technique employed was as follows: The patient being in a recumbent position, a rectal tube, well greased, is introduced into the rectum for a distance of about three inches. (It is unnecessary to insert the tube as far as eleven or twelve inches as recommended by Bastedo). After the tube has been introduced the patient lies on his back, an atomizer bulb is attached to the free end of the tube, which is brought up between the legs and air is slowly pumped in. In individuals with no appendicular disease there is no pain apart from a feeling of fulness in the lower bowel, with at times a sensation as if defecation was imperative.

In patients suffering from appendicitis it is claimed that there is an almost immediate complaint of spontaneous pain in the right iliac fossa, much exaggerated by finger-point pressure. In those cases of appendicitis with epigastric pain, pain is not complained of in the epigastrium, but in the right iliac fossa, and in cases with pain located in this region the discomfort is intensified. At times pain on pressure over the distended cecum induces pain, not over McBurney's point, but also in the epigastrium as well; this phenomenon being only seen, however, when epigastric pain has been a preëxisting symptom. Aaron ${ }^{9}$ has already described as a sign of chronic appendicitis epigastric pain which follows pressure in the right iliac fossa.

While pursuing our studies it was deemed advisable to examine every patient admitted to the medical ward, provided he complained of no abdominal distress. By doing this we collected about seventy-five cases, presumably normal, so far as the appendix was concerned, and in none was pain complained of in the right iliac fossa following inflation. We feel that this number of cases justifies the belief supported by the experience of Bastedo and of Hertz that normal individuals do not have what may be called positive tests. We therefore discontinued our observations on control cases.

In studying the abdominal cases admitted to the hospital, our work was much facilitated by the ready willingness of the various chiefs of the Presbyterian Hospital, who at all times gladly placed their material at our disposal. We cannot express too strongly our appreciation of the many courtesies extended by Drs. Hodge, Rodman, Jopson, Shoemaker, and Girvin, in whose wards many of the operative cases were observed.

Our results briefly put are not in accordance with those of other writers. There have been in our series of positive tests 3 cases which have had no indication of appendicular lesion; notably 1 
case of cholelithiasis, 1 of nephritis (signs present one day, absent the next; patient later died of uremia), and 1 of right-sided pneumonia, with pain in the right iliac fossa.

Of the negative cases, 7 had appendices chronically inflamed and bound down by adhesions and 5 were suffering with acute appendicitis.

Salpingitis, in our experience, does not give typical pain in the right side. It is true that pain is complained of, but it is low down in the abdomen and not in the region of McBurney's point. We have felt that the sign may have some value in distinguishing between this condition and appendicitis.

Conclusions. 1. Inflation of the colon is an equivocal means of diagnosing chronic appendicitis. Some cases have negative tests and some have positive; there seems to be no constancy in the result obtained.

2. In acute appendicitis the method should not be employed. It is rarely necessary as a diagnostic aid, as the results are uncertain and the risk of injurying the intestine is too great.

3. The method should not be considered useless, however, for at times the diagnosis has been materially strengthened by its employment, and operation has later shown the wisdom of our faith in the result obtained. Inflation of the colon, however, should be regarded merely as an aid in the diagnosis, history and physical examination being far more valuable.

4. We have seen no positive reactions in normal individuals.

5. The test is in no sense pathognomonic of chronic appendicitis.

\section{DUODENAL ALIMENTATIONS. ${ }^{1}$}

\section{By William Gerry Morgan, M.D., WASEINGTON, D. C.}

Perhaps the best of the many excellent things which Einhorn has contributed to the science and practice of medicine is the duodenal tube and its practical application to the relief of certain disorders of the alimentary tract. Duodenal alimentation has been practised during the past four years by an increasing number of medical men throughout the United States, Canada, and Europe, and wherever it has been intelligently carried out it has gained a permanent place in the treatment of suitable cases. Whenever duodenal alimentation has failed it has been due, in my opinion,

\footnotetext{
${ }^{1}$ Read by invitation before the Pittsburgh College of Physicians, February 26, 1914.
} 